\title{
Research and Implementation of Tobacco Leaf Value Chain Management Based on ERP and PDM in Tobacco Industry Enterprise
}

\author{
Yong Cen \\ Information Center China Tobacco Zhejiang Industrial Co, Ltd, Hangzhou, 310009, PR China \\ ceny@zjtobacco.com
}

\begin{abstract}
Nowadays tobacco enterprises are required to enhance the level of tobacco leaf management in order to increase their competitiveness in complex markets. Tobacco leaf value chain management plays a fundamental role in this process as the correct implementation of strategies is determined by the information transfer and integration within the enterprise. This paper presents the tobacco leaf value chain management model by through the collaboration of ERP and PDM system with SAP XI as the enterprise service bus. Under this collaboration management model, PDM system manage the whole life cycle of tobacco leaf, and in ERP system, manage all business processes, systems interactive information by the way of Web Services. Therefore, logistics, capital flow and information flow can be better unified management in tobacco leaf management. And this model could achieve the information support for tobacco resource procurement management and aimed at reduce the operating costs of production, thereby enhancing the market competitiveness of the cigarette products.

Index Terms - Tobacco leaf, Value chain management, ERP, PDM
\end{abstract}

\section{I . Introduction}

Value chain means to the transfer of the costs and profits in every aspect of the formation in business activities constitute value in the enterprises, and value chain management refers to the value delivery process to sort out the various aspects of business operation and control, and to maximize the value. The core of value chain management is the cost management based on the characteristics of business operations [1]. In the tobacco industry, tobacco value chain refers to the costs and profits in every aspect of a business formed value transfer from the tobacco leaf procurement planning to strips receipt storage. Therefore, tobacco leaf value chain management refers to optimize and control the various aspect of business operation from the tobacco origin management to put into production, and to maximize the value. The purpose of tobacco leaf value chain management in tobacco industry enterprises is to optimize the core business processes of tobacco leaf procurement, to integrate financial services operation, to reduce the operating costs of production, and to provide high-quality raw materials, so as to enhance the market competitiveness of the cigarette products.

At present, the domestic tobacco industry enterprises continue to strengthen information technology, and achieved good results, however, the information construction of the tobacco procurement process management is still in its infancy, and many tobacco enterprises have carried on the unremitting exploration and practice information construction in tobacco leaf management. Research on quality system realized for sorting, writing, mending, inquiring and statistics computing of tobacco leaf quality data, evaluating the tobacco quality and producing area of tobacco [2-4]. Research on [5] in order to effectively prevent the violations of provision and discipline in tobacco leaf purchasing, an internal supervision system was designed. Research on [6] a new predictive control algorithm is proposed based on process model to fit the special dynamical character of the tobacco re-drying system. Research on [7] developed a RFID-based leaf tobacco logistics information system platform, in order to improve the reliability and accuracy of tobacco warehousing and logistics information and solve the problems existed in logistics process, including complicated data acquisition, ineffective tobacco supply chain monitoring, and untraceable tobacco logistics information.

In this paper, through the integration of PDM and ERP systems to achieve new tobacco enterprise resource management model, to solve the problems existing in the management process for a long time, finally realizes the purpose of the strengthen enterprise strategic cost management and enhance core competitiveness in complex market.

\section{II . Current Problem Analysis}

Tobacco leaf resources as tobacco industry enterprise one of strategic goods and materials, is an important object in enterprise supply chain management. Tobacco industry enterprises there are some problems in the tobacco leaf resource management: Tobacco leaf is one type of agricultural products, which place of origin, variety and more grades, and high quality resource is limited every year. There is no whole life cycle management of the tobacco leaf in the enterprise. Under the system of state-owned monopoly, the tobacco procurement management there is many objective factors constraints. The raw tobacco leaf entire delivery cycle is a very long term, and bulks of the contracts always are the purchase complete before settlement, inconsistent with the account content, and the adjustment is difficult.

\section{III . Tobacco Leaf Value Chain MJanagement in Tobacco JIndustry Enterprise}

The core goal of tobacco leaf value chain management in tobacco industry enterprise is to realize the logistics, value flow and information flow harmonious and unified, 
optimization of the whole business chain operation and management of the processes, reduce business operating costs, and promote the competitiveness of the supply chain. According to the overall plan of the enterprise information planning and information system construction actual situation, building and collaboration of PDM and ERP system to achieve the life-cycle management and tobacco leaf resources value chain management content.

\section{A. Tobacco Life - Cycle Management in Product Data Management System ( PDM)}

In the fierce market competition, the enterprise product quality, costs, research and development so on place high demands. Enterprises are also aware of the brand's research and development in the enterprise's core competitiveness. It is essential that improve the product design process to shorten the product development and manufacturing cycles, improve product quality and improve product performance. It makes the needs of workflow increased, for collaborative software produces more pressing needs. Most enterprises have been widely implemented PDM system to manage the productrelated data and design process. PDM system aims at managing and storing the product data and also information related its entire lifecycle (manufacturing, assembly, maintenance, etc.).

Enterprises through the construction and application of the PDM system, manage the content of tobacco leaf from the place of origin, demand planning, quality management, tobacco processing BOM to the product formulation design in the entire life cycle of tobacco leaf. The framework of the tobacco leaf lifecycle management in PDM as the Figure 1 shown:

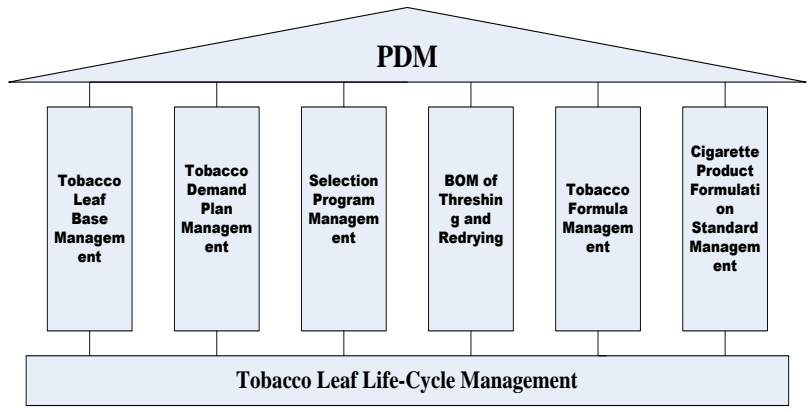

Fig.1 The framework of the tobacco leaf lifecycle management in PDM.

1) Tobacco Leaf Base Information Management: Collection and management of tobacco leaf base related information such as the geographical and natural conditions. Management base evaluation index system, scientific management of the various tobacco base.

2) Tobacco Demand Plan Management: According to the needs of enterprise development strategies and cigarette brand development, analysis of the demand for tobacco and to develop appropriate procurement plan for tobacco leaf.

3) Selection Program Management: Develop appropriate selection of information according to the tobacco of the physical indicators, and clear changes between the levels of various tobacco leaves.

4) Threshing and Redrying BOM Management: According to the tobacco selection and grade information and develop scientific threshing and redrying formula, then, to guidance processing plant according to the requirements for the processing of tobacco leaves.

5) Tobacco Formula Management: Management the design and development of tobacco leaf formula for different cigarette products.

6) Cigarette Product Formulation Management: The cigarette product formulation involving four major contents which includes tobacco materials formulation, tobacco flavors formulation, tobacco leaf formulation and process parameters.

\section{B. Tobacco Leaf Procurement Management in ERP System}

According to the tobacco leaf value chain management design ideas and actual situation of enterprises, tobacco leaf procurement management overall framework divided into three layers: Planning Layer, Execution Layer and Accounting Layer. Planning layer means to the process from tobacco leaf purchasing demand plan to tobacco leaf procurement agreement. Execution layer refers to the process from sign the contract to receipt, selection, threshing and redrying. Accounting layer means to the implementation of business financial accounting process. The tobacco procurement process management as the Figure 2 shown:

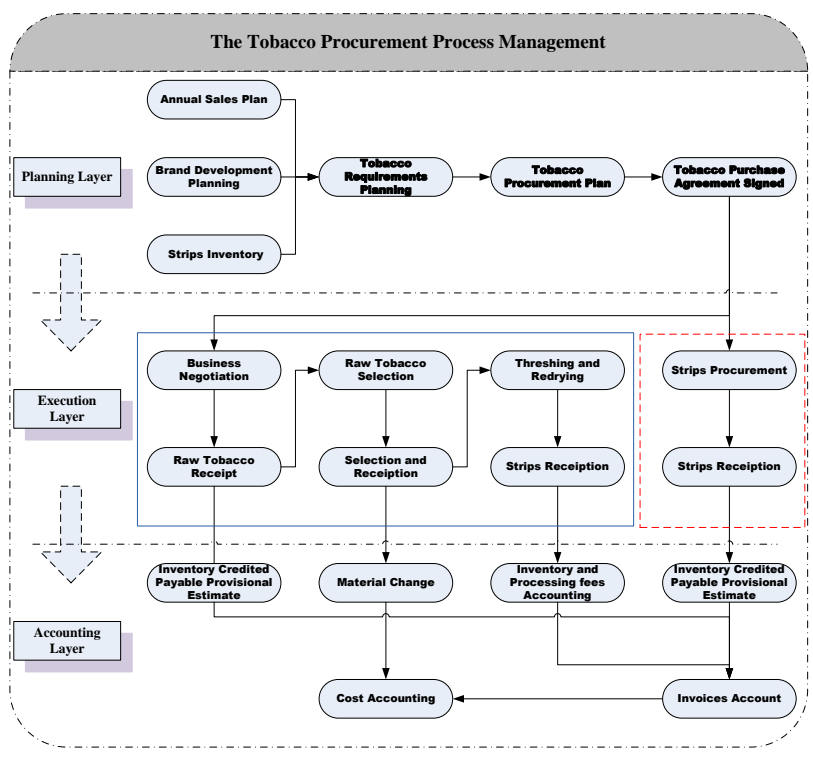

Fig.2 Tobacco procurement process

1) Integration of Planning and Execution: According to the National Bureau assigned the annual purchase amount and suppliers, tobacco leaf annual purchasing agreement with all suppliers on the Internet, and according to the Purchase Agreement executed tobacco leaf purchasing. Based on the implementation of purchasing plan and the actual purchasing matched controls, tracking the annual procurement plan and 
procurement implementation, and declare to prepare for next year's procurement plan.

2) Integration of Financial Business: Integration of financial business is the basis of centralized management and control of procurement of tobacco leaf. In ERP system, the outcome of the negotiations based on the real-time allocation of the tobacco business as a starting point. Settlement, to guarantee payment invoices, purchase orders, receiving information three single match and clear process information. At the same time need to meet financial management requirements for the transit consumption, level adjustment, the actual cost of tobacco.

3) Integration of Business Supply Chain: By subdividing the original tobacco leaf material code and setting up the virtual location refinement of inventory management. In tobacco leaf receiving, selection and redrying processing and other sectors, fully demonstrated the tobacco process management information, to improve the information query mechanism to improve the traditional forms of information gathering, improve work efficiency.

\section{PDM and ERP System Information Integration}

The tobacco leaf value chain management has very complicated business logic, numerous different systems, and high requirements of users. These features make the information integration of information systems very difficult. According to the thought of loose coupling, Service Oriented Architecture (SOA) can ensure the flexibility, as well as control the complexity [8]. So take the SOA architecture for PDM and ERP system information integration will be the best choice. The core of information integration is the construction of Enterprise Service Bus (ESB) and unified service registry management system. Therefore, based on the construction of the status quo of system and combined with features of SAP $\mathrm{XI}$, use the SAP XI as the enterprise service bus (ESB), through the SOAP protocol and star-shape structure to realize the integration of related system [9]. After each application system present situation research, demand discussion and blueprint design, the formation of the final solving strategies based on the system integration of SAP XI, as the Figure 3 shown:

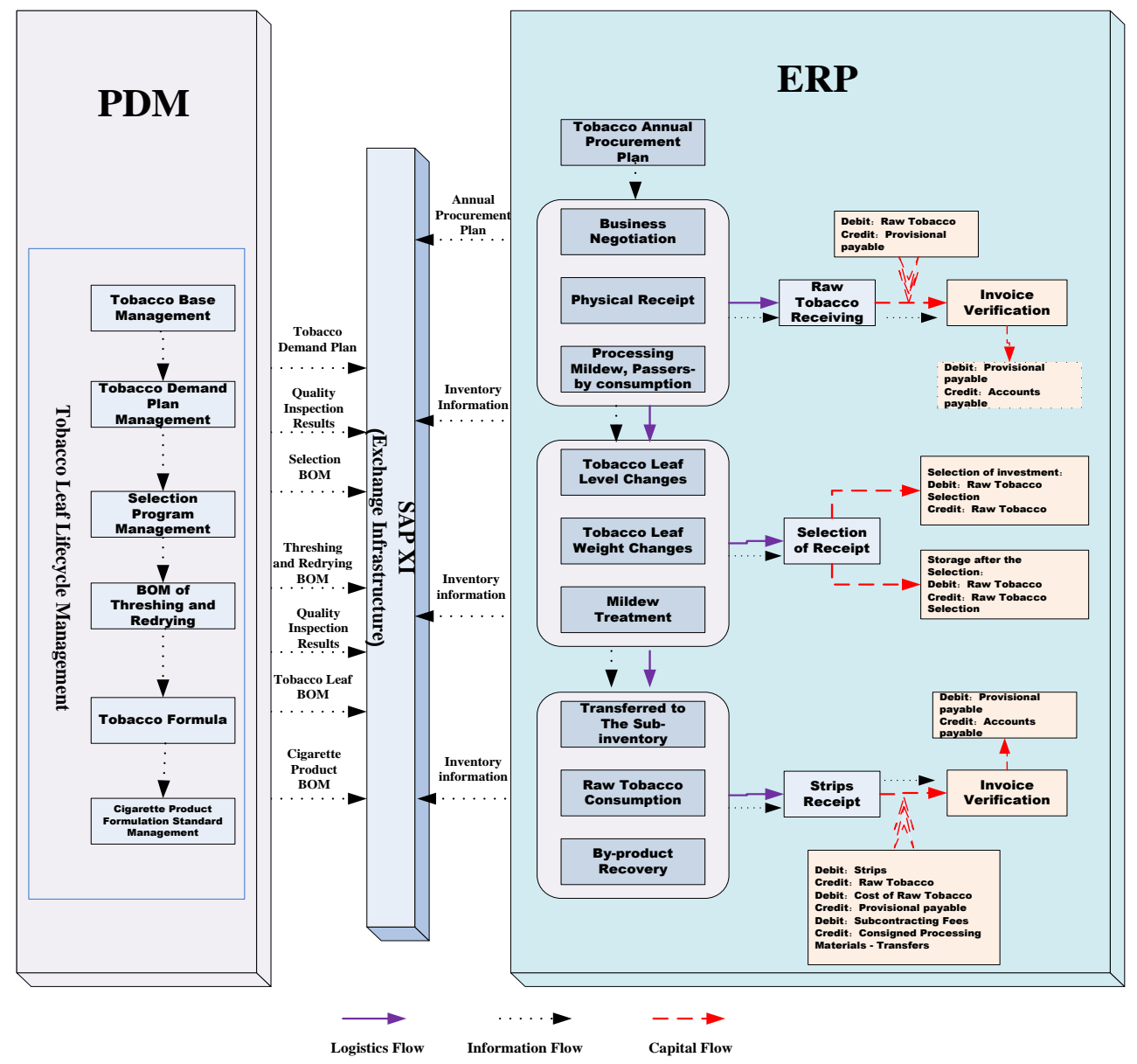

Fig.3 The information integration of PDM and ERP

Tobacco leaf value chain management consists mainly of raw tobacco plan, receiving, selection, of roasting and financial settlement link. There are two main type of business in the procurement process, one type is called "raw tobacco transfer, raw tobacco settlement", another type is "raw tobacco transfer, strips settlement". In order to meet the needs of 
procurement management, in the ERP system, the type of raw tobacco transfer, strips settlement reference raw tobacco transfer, raw tobacco settlement for physical management, material does not represent the value attributes, and not for value management in the stage of raw tobacco leaf receiving and selection. The specific contents are as follows:

1) Raw Tobacco Leaf Plan: Annual purchase amount allocated in accordance with the National Bureau signed tobacco annual purchase agreements with various suppliers on the Internet, and executed in accordance with the purchase agreement for the purchase of raw tobacco. In the system according to the annual purchase agreement, created a procurement plan, including the grade and quantity of raw tobacco leaves.

2) Raw Tobacco Leaf Purchase: In the ERP system, the business results of the negotiations as a starting point, to record negotiations grade and quantity of material information. Created purchase orders based on the actual quantity received, and modify the purchase order entry should bear the number of transit consumption and rotten quantity of raw tobacco leaves, receipt upon completion of a level change materials to restore the original level, which merged into the original levels, while consumption scrapped transit, and automatically generate the corresponding accounting documents to ensure the system inventory and physical inventory.

3) Raw Tobacco Leaf Selection: In the stage of selection of raw tobacco to meet the needs of the management, system will record the material grade weight and other factors change before and after the selection, and thereby calculating the value change before and after selection.

4) Threshing and Redrying: Create work orders in the system, according with threshing and redrying BOM, and transferred to the subcontracting stock. Then, after the completion of the threshing, will receipt the strips and byproducts outsourcing, while automatically generate the corresponding accounting documents. In the system, create leaf processing is obtained by the match play plan sheet, then feeding into the subcontract inventory, waiting for after the completion of the smoke to pills smoke receiving outsourcing and by-products, and consume the subcontract of the smoke, automatically generate corresponding accounting vouchers at the same time.

5) Financial Settlement: In the ERP system, in order to facilitate the purchase cost of accounting, there are three main settlement approaches:

- Payment for Goods: In ERP system, using purchase order receipt-based invoice verification, payment invoices, purchase orders, receiving three single one, to ensure that the three single match.

- Strips Outsourcing Processing Fees: Using outsourcing of processing purchase orders for invoice verification.

- Other Expense: Subsequent debit purchase invoice verification, expense records to the difference between subjects, and then comes down to the cost of materials.

Through above three ways, the original purchase of raw tobacco leaf each fee into the purchasing cost, automatically generate accounting documents after the invoice verification, so that the financial monitoring to the sum of procurement operations, and can be positive and negative retrospective.

\section{Implementation Result Analysis}

The management model achieves the tobacco lifecycle information management, which managing critical information throughout the tobacco cycle, such as the BOM, quality information and changes between the levels of various tobacco leaves.

Enhance the efficiency and all aspects of the entire tobacco supply chain management. In the model, gives advanced procurement management approach, can real time to reflect changes in inventory process, and improve the process of consumption management.

Better management logistics, information flow and capital flow unity in the process of tobacco resource management. Make financial can monitor to each purchasing business, and can carries on the forward and reverse traceability.

\section{Conclusions}

This paper presents an approach to manage the tobacco leaf resource in tobacco industry enterprise by integrating ERP and PDM system with SAP XI as the ESB. The collaboration management model has been applied to tobacco leaf value chain management it can help enterprise to obtain valuable information about levels of strategy, flexibility and performance required in the supply chain management of tobacco leaf. In the collaboration management model, will optimize the core business processes of tobacco procurement, to reduce the operating costs and to enhance the market competitiveness of the cigarette products in complex market.

\section{References}

[1] Zhu Junfeng. China's tobacco industry development research, 2008.

[2] Wang Jun, Peng Qianrong, Shi Yanfu et.al. Development of Tobacco Leaf Quality Data Management System. Tobacco Science \& Technology, 2004(07), pp.17-20

[3] Li Xiaolan,Sun Jiansheng, Liang Wei. A study on building quality assurance system for industrial tobacco raw materials. Guangdong Agricultural Sciences, 2008(11), pp.142-144.

[4] Lu Shaokun, Li Zhengfeng, Song Pengfei et.al. The Development and Implementation of Evaluation System of Tobacco Quality and Producing Area of Tobacco Based on MySQL and Delphi. Chinese Agricultural Science Bulletin, 2011(27), pp.451-455.

[5] Ding Wei, Xiao Qiang, Li ShiXiang et.al. Design and Application of Internal Supervision System for Tobacco Leaf Purchasing. Tobacco Science \& Technology, 2011(07), pp.24-27.

[6] Wei Junhong, Ren Zhengyun, Shi Jianping. Research of Predictive Control in Tobacco Re-drying System. Control Engineering of China, 2010(05), pp.68-71.

[7] Wu Liang, Zhou Hong, and Zhang Bing. Design and Realization of RFID-based Tobacco Logistics Management Information System. Tobacco Science \& Technology, 2011-09.

[8] Hua-dong Wang, Qiang Hu. Research and Application of an Integration Platform for E-Commerce System Based on SOA. International Conference on Management of E-commerce and E-government, 2009:424-427.

[9] John Wiley, Sons. SAP NetWeaver For Dummies. Wiley Publishing, 2005 . 